\title{
BIOTRANSFORMATION OF BILE ACIDS BY CLOSTRIDIA
}

\author{
R. W. OWEN \\ PHLS Centre for Applied Microbiology and Research, Bacterial Metabolism Research \\ Laboratory, Porton Down, Salisbury, Wiltshire SP4 OJG
}

\begin{abstract}
SummaRy. The metabolism of bile acids by nuclear dehydrogenating clostridia (NDC) was studied. NDC were able to desaturate the A-ring of $5 \beta$-cholan-3-oxo-24-oic acid, $12 \alpha$-hydroxy-5 $\beta$-cholan-3-oxo-24-oic acid, $7 \alpha$-hydroxy-5 $\beta$-cholan-3-oxo-24-oic acid, $6 \alpha$-hydroxy-5 $\beta$-cholan-3-oxo-24-oic acid, $7 \alpha, 12 \alpha$-dihydroxy-5 $\beta$-cholan-3-oxo-24-oic acid, 3,12 -dioxo-5 $\beta$-cholan-24-oic acid but not 3,6-dioxo-5 $\beta$-cholan-24-oic acid, 3,7-dioxo-5 $\beta$-cholan-24-oic acid and 3,7,12-trioxo-5 $\beta$-cholan-24oic acid. In each case the sole product possessed a 4-ene-3-one structure. Desaturation of bile acids was more efficient than that of androstanes. NDC are, therefore, capable of introducing double bonds into the nucleus of bile acids as well as that of androstanes. The physiological significance of such reactions in relation to large bowel cancer has yet to be elucidated.
\end{abstract}

\section{INTRODUCTION}

Certain clostridia, indigenous to the human intestine are capable of oxidising the A-ring of steroids to give a 4-ene-3-one configuration (Aries et al., 1971; Goddard et al., 1975). Such organisms are termed nuclear dehydrogenating clostridia (NDC). The ability to perform nuclear dehydrogenation (NDH) is present in $>90 \%$ of lecithinasenegative clostridia but in only c. $3 \%$ of lecithinase-positive clostridia (Goddard et al., 1975). The presence in the bowel of clostridia able to perform NDH forms an intergral part of the hypothesis put forward by Aries et al. (1969) that implicates unsaturated bile acids in colon carcinogenesis. Persons suffering from colon cancer have a carriage rate of NDC $40 \%$ higher than control populations (Hill et al., 1971).

Previous reports (Aries et al., 1971; Goddard et al., 1975) have been concerned with the desaturation of androstanes because they are more water-soluble and thus easier to study than bile acids. However, NDC do not oxidise the $3 \alpha$-hydroxyl group of bile acids (Macdonald and Hill, 1978) because a $\mathrm{C}_{3}$ oxo-group is required to induce NDH enzymes. There is, however, abundant evidence that 3-oxo-bile, acids are produced in vivo (Eneroth et al., 1966) and in vitro (Macdonald et al., 1979) by lecithinase-positive clostridia and other genera common in the human intestinal tract.

The present study was undertaken to ascertain whether clostridia indigenous to the human intestine can metabolize bile acids in anaerobic conditions. 


\section{MATERIALS AND METHODS}

Steroids. 5 $\beta$-Androstan-3,17-dione, 17 $\beta$-hydroxy- $5 \beta$-androstan-3-one, androst-4-ene-3,17dione, $17 \beta$-hydroxyandrost-4-ene-3-one and androsta-1,4-diene-3,17-dione were obtained from Koch-Light Laboratories Ltd (Colnbrook, Bucks). Cholic acid $(3 \alpha, 7 \alpha, 12 \alpha$-trihydroxy-5 $\beta$-cholan-24-oic acid), chenodeoxycholic acid ( $3 \alpha, 7 \alpha$-dihydroxy-5 $\beta$-cholan-24-oic acid), deoxycholic acid $(3 \alpha, 12 \alpha$-dihydroxy-5 $\beta$-cholan-24-oic acid), hyodeoxycholic acid $(3 \alpha, 6 \alpha$-dihydroxy- $5 \beta$-cholan-24-oic acid) and lithocholic acid ( $3 \alpha$-hydroxy-5 $\beta$-cholan-24-oic cid) were obtained from Steraloids Ltd, Worthing, Sussex.

The 3-oxo-derivatives of bile acids were prepared by selective oxidation of the $3 \alpha$-hydroxyl group with silver carbonate on celite (Tserng, 1978). The identity of the products was confirmed by spectroscopy and gas-chromatography-mass spectrometry by comparison with authentic standards (Owen, 1980).

Bacterial strains. The organisms selected for study comprised nine NDH-positive and two NDH-negative strains. The NDH-positive strains were Clostridium paraputrificum strains 16, $17,7,1172,10,1090$ and $510 ; C$. tertium strain 667 and $C$. butyricum strain 493 . The NDH-negative strains were $C$. perfringens strain $11 / 11$ and $C$. paraputrificum strain 1152 . The strains were isolated from human faeces by the methods of Drasar and Crowther (1971) and identified by the methods of Holdeman and Moore (1975).

Growth conditions. An exponential-phase cooked-meat culture $(500 \mu \mathrm{l})$ was added to $4.0 \mathrm{ml}$ of freshly steamed Todd-Hewitt Broth containing steroid $50 \mu \mathrm{g} / \mathrm{ml}$ as inducer. The cultures were incubated in an atmosphere of $\mathrm{H}_{2} 90 \% \mathrm{CO}_{2} 10 \%$ for $24 \mathrm{~h}$ at $37^{\circ} \mathrm{C}$. To this culture was added 500 $\mu \mathrm{l}$ of an ethanolic solution containing steroid as substrate and menadione (as artificial electron acceptor) to give a final concentration of steroid $0.01 \%$ and menadione $0.35 \%$. The cultures were re-incubated for $18 \mathrm{~h}$ and the products were extracted twice with equal volumes of ethyl acetate. The extracts were dried over anhydrous $\mathrm{MgSO}_{4}$ and solvent was removed in vacuo on a Buchi rotary evaporator.

Analysis and identification of bile-acid products. Culture extracts were analysed by thin-layer chromatography (TLC) on Polygram Sil/ $\mathrm{UV}_{254}, 0.25-\mathrm{mm}$ plastic backed plates (Camlab, Cambridge) with the developing solvents, methanol-dichloromethane $(1: 19 \mathrm{v}: \mathrm{v})$, benzene-dioxan-water (100:10:1 v:v:v) and 2,2,4-trimethylpentane-ethyl acetate-acetic acid (45:45:10 v:v:v). Unsaturated bile acids were located under ultraviolet light at $254 \mathrm{~nm}$; the TLC plates were then sprayed with anisaldehyde reagent (Kritchevsky et al., 1963) and heated for $10 \mathrm{~min}$ to locate all steroids. TLC made possible the presumptive identification of products by comparing colour characteristics and mobilities with authentic standards.

Bile-acid products were analysed quantitatively as their methyl esters by gas-liquid chromatography (GLC) on a Pye 204 gas chromatograph fitted with a $2 \mathrm{M} \times 4 \mathrm{~mm}, 3 \% \mathrm{OV}-1$ 100-120 mesh supelcoport glass column at $260^{\circ}$. Before GLC, bile acids and their bacterial products were methylated with diazomethane in ether by the method of De Boer and Backer (1954).

Infra red spectra were obtained on $\mathrm{KBr}$ discs with a Unicam SP 1200 spectrophotometer. Ultra-violet spectra were measured in methanolic solutions in silica cells (path length $1 \mathrm{~cm}$ ) with a SP 1800 recording spectrophotometer.

GC-mass spectra were obtained with a Dupont 21-491 series mass spectrometer equipped with a $21-0948$ data system and coupled to a Varian aerograph 2700 gas chromatograph.

\section{RESULTS}

The results show that NDC were able to desaturate, at $\mathrm{C}_{4}-\mathrm{C}_{5}$, a range of bile acids carrying on oxo group at $\mathrm{C}_{3}$ (table). Of the nine $\mathrm{NDH}$-positive strains tested each was able to desaturate $5 \beta$-cholan-3-oxo-24-oic acid to chol-4-ene-3-one-24-oic acid, $12 \alpha$-hydroxy-5 $\beta$-cholan-3-oxo-24-oic acid to $12 \alpha$-hydroxychol-4-ene-3-one-24-oic acid, $7 \alpha$-hydroxy-5 $\beta$-cholan-3-oxo-24-oic acid to $7 \alpha$-hydroxychol-4-ene-3-one-24-oic acid and $6 \alpha$-hydroxy-5 $\beta$-cholan-3-oxo-24-oic acid to $6 \alpha$-hydroxychol-4-ene-3-one-24- 


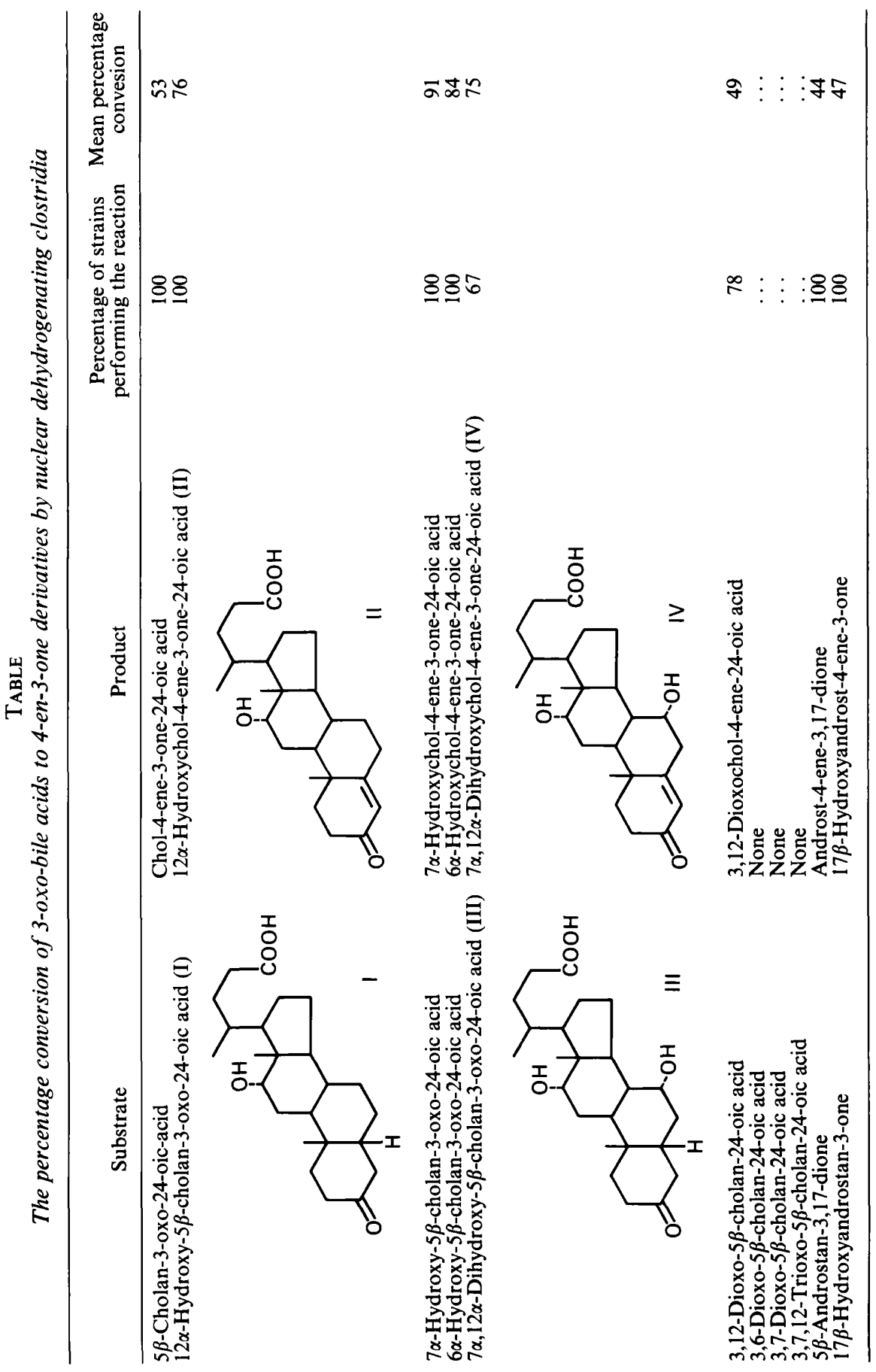


oic acid. Two other bile-acid substrates were metabolised by NDC. However, only $67 \%$ of the NDC were capable of desaturating $7 \alpha$-12 $\alpha$-dihydroxy-5 $\beta$-cholan-3-oxo-24-oic acid to $7 \alpha-12 \alpha$-dihydroxychol-4-ene-3-one-24-oic acid and $78 \%$ of desaturating 3,12-dioxo-5 $\beta$-cholan-24-oic acid to 3,12-dioxochol-4-ene-24-oic acid.

The 3-oxo bile acids that also possessed a 6-oxo group (3,6-dioxo-5 $\beta$-cholan-24-oic acid) or a 7-oxo group (3,7-dioxo-5 $\beta$-cholan-24-oic acid and 3,7,12-trioxo-5 $\beta$-cholan-24-oic acid) were not desaturated byNDC.

It is of interest that NDC gave a higher percentage conversion (mean $25 \%$ ) of 3-oxo bile acids than of androstanes. NDH-negative strains did not desaturate 3-oxo bile acids or androstanes.

\section{Discussion}

The results show that NDC, mainly strains of $C$. paraputrificum, oxidise the A-ring of 3-oxo bile acids efficiently to yield products with a 4-ene-3-one structure. Oxidation of 3-oxo bile acids is more efficient than that of androstanes and the presence of single hydroxyl groups at $\mathrm{C}_{6}, \mathrm{C}_{7}$ and $\mathrm{C}_{12}$ appears to enhance enzyme induction and activity. Oxo-groups at $\mathrm{C}_{6}$ and $\mathrm{C}_{7}$ completely inhibit the $\mathrm{NDH}$ reaction, presumably because of the proximity of such groups to the enzyme binding site. Experiments to test this conclusion showed that, even after enzyme induction, oxidation was completely inhibited. The presence of a 12-oxo group on a 3-oxo bile acid inhibited oxidation by $22 \%$ of the clostridia, whilst the presence of hydroxy groups at $\mathrm{C}_{7}$ and $\mathrm{C}_{12}$ inhibited the $\mathrm{NDH}$ reaction in $33 \%$ of the clostridia. These results were consistent in six experiments and indicate that the ability of NDC to perform the NDH reaction depends, to a certain degree, on the number and type of substituent groups carried by a 3-oxo bile acid. In the described conditions, products of the 4-ene-3-one configuration only were detected without evidence for the presence of 1,4-dienone intermediates. Unsaturated $\mathrm{C}_{22}$ and $\mathrm{C}_{19}$ intermediates were not detected indicating that NDC are unable to degrade the side-chain of bile acids. This was confirmed by quantitative recovery of substrate plus product from the fermentations.

This study conclusively shows that, in vitro, NDC can efficiently desaturate the A-ring of the 3-oxo derivatives of the major colonic bile acids-lithocholic acid, deoxycholic acid, chenodoeoxycholic acid and cholic acid. There is no evidence to suggest that these reactions take place in the large bowel because the unsaturated bile acids described in this report have not been detected in faeces. There may be several reasons for this. The amounts of artificial electron acceptor used in this and other studies (Aries et al., 1971; Goddard et al., 1975) are probably unphysiological and represent a much higher concentration than the available electron source in colonic contents. Moreover, the techniques employed for faecal bile-acid analysis may degrade unsaturated bile acids, and unsaturated intermediates, if produced in vivo by NDC, may be transient because of immediate reduction by other colonic bacteria.

Several studies (Fernandez and Hill, 1978; Fernandez et al., 1985) have been conducted in an attempt to evaluate the concentration of faecal electron acceptors which are mainly plant and bacterial quinones. Absolute measurement of quinones has proved technically difficult because the quinones are unstable. It is, therefore, premature to conclude that their colonic concentration is too low to support the NDH reaction in vivo. 
Recently, several reports have highlighted the advances made in faecal bile-acid analyses (Setchell et al., 1983; Owen et al., 1984). The techniques now employed involve mild extraction steps and fractionation of faecal steroids by diethylaminohydroxypropyl (DEAP-LH-20) sephadex column chromatography and it is known that unsaturated bile acids survive such processing (Owen, unpublished). Unsaturated bile acids have not been detected in faeces probably because their appearance is only transient. It has recently been shown (Owen and Bilton, in press) that, when unsaturated 4-ene-3-one, 1,4-diene-3-one and 4,6-diene-3-one bile acids are co-incubated with mixed faecal bacteria in vitro, they become fully reduced within $72 \mathrm{~h}$. Metabolism to the fully reduced products is, however, substantially inhibited in the presence of menadione. Evidence for the transient appearance of unsaturated bile acids in faeces has been supplied by Kallner (1967) who demonstrated that intestinal bacteria are responsible for the inversion of $5 \beta$-bile acids to $5 \alpha$-bile acids (allo-bile acids) via 4-ene-3-one intermediates. It is, therefore, possible that NDC may be an important group of organisms responsible for the small amounts of allo-bile acids detected in faeces.

It has recently been demonstrated that allo-bile acids have co-mutagenic activity (Wilpart et al., 1983) and it is possible that the positive correlation observed between high NDC carriage and colon cancer (Aries et al., 1969; Hill et al., 1971) is due more to allo-bile acid than to unsaturated bile-acid formation. This view is favoured by recent evidence that unsaturated bile acids are not potent mutagens (McKillop et al., 1983); however, their role as co-mutagens has yet to be evaluated.

Studies are in progess to elucidate the effect of carbohydrates, fibre and other intestinal bacteria on the metabolism of 3-oxo-bile acids by Clostridium species.

This work was funded by the Cancer Research Campaign.

\section{REFERENCES}

Aries V C, Crowther J S, Drasar B S, Hill M J, Williams R EO 1969 Bacteria and the aetiology of cancer of the large bowel. Gut 10:334-335.

Aries V C, Goddard P, Hill M J 1971 Degradation of steroids by intestinal bacteria. III. 3 -oxo-5 $\beta$-steroid- $\Delta^{1}$-dehydrogenase and 3 -oxo-5 $\beta$-steroid- $\Delta^{4}$-dehydrogenase. Biochemica et Biophysica Acta 248:482-488.

De Boer T J, Backer H J 1954 A new method for the preparation of diazomethane. Recueil des Travaux Chimiques des Pays-Bas 73:229-234.

Drasar B S, Crowther J S 1971 The cultivation of human intestinal bacteria. In: Shapton $\mathcal{A}$ A, Board R G (eds) Isolation of anaerobic organisms, Society of Applied Bacteriology Technical Series No. 5, Academic Press, London, pp 93-97.

Eneroth P, Gordon B, Rhyage R, Sjovall J 1966 Identification of mono- and dihydroxy bile acids in human feces by gas-liquid chromatography and mass spectrometry. Journal of Lipid Research 7:511-523.

Fernandez F, Collins D, Hill M 1985 Production of vitamin K by human gut bacteria. Biochemical Society Transactions 13:223-224.

Fernandez F, Hill M $1978 \mathrm{~A}$ faecal hydrogen acceptor for clostridial 3-oxo steroid $\Delta^{4}$-dehydrogenase. Biochemical Society Transactions 6:376-377.

Goddard P, Fernandez F, West B, Hill M J, Barnes P 1975 The nuclear dehydrogenation of steroids by intestinal bacteria. Journal of Medical Microbiology 8:429-435.

Hill M J, Drasar B S, Aries V, Crowther J S, Hawksworth G, Williams R E O 1971 Bacteria and aetiology of cancer of large bowel Lancet 1:95-100.

Holdeman L V, Moore W E C 1975 Anaerobe laboratory manual, 3rd edn. Virginia Polytechnic Institute, Blacksburg, VA. 
Kallner A, 1967 Bile acids and steroids. CLXXV. On the biosynthesis and metabolism of allodeoxycholic acid in the rat. Acta Chemica Scandinavia 21:315-321.

Kritchevsky D, Martak D S, Rothblat G H 1963 Detection of bile acids in thin-layer chromatograhy Analytical Biochemistry 5:388-392.

Macdonald I A, Hill M J 1978 The inability of nuclear dehydrogenating clostridia to oxidize bile salt hydroxyl groups. Experientia 35:722-723.

Macdonald I A, Jellett J F, Mahony D E, Holdeman L V 1979 Bile salt $3 \alpha-$ and $12 \alpha$-hydroxysteroid dehydrogenases from Eubacterium lentum and related organisms. Applied and Environmental Microbiology 37:992-1000.

McKillop C A, Owen R W, Bilton R F, Haslam E A 1983 Mutagenicity testing of steroids obtained from bile acids and cholesterol. Carcinogenesis 4:1179-1183.

Owen R W 1980 The anaerobic degradation of steroids. PhD Thesis, Council for National Academic Awards. Liverpool Polytechnic.

Owen R W, Bilton R F 1984 Metabolism of unsaturated bile acids and androstanes by human faecal bacteria. Journal of Steroid Biochemistry In press.

Owen R W, Thompson M H, Hill M J 1984 Analysis of metabolic profiles of steroids in faeces of healthy subjects undergoing chenodeoxycholic acid treatment by liquid-gel chromatography and gas-liquid chromatography-mass spectrometry. Journal of Steroid Biochemistry 21:593-600.

Setchell K D R, Lawson A M, Tanida N, Sjovall J 1983 General methods for the analysis of metabolic profiles of bile acids and related compounds in feces. Journal of Lipid Research 24:1085-1100.

Tserng K Y 1978 A convenient synthesis of 3-keto bile acids by selective oxidation of bile acids with silver carbonate-Celite. Journal of Lipid Research 19:501-504.

Wilpart M, Mainguet P, Maskens A, Roberfroid M 1983 Structure-activity relationship amonst biliary acids showing co-mutagenic activity towards 1,2-dimethylhydrazine. Carcinogenesis 4:1239-1241. 